\title{
Computational, Analytical and Experimental Investigation of Heat Conduction of Particulate Filled Polymer Composite
}

\author{
Alok Agrawal", Alok Satapathy \\ Department of Mechanical Engineering, National Institute of Technology Rourkela, India
}

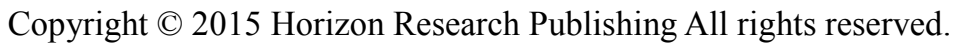

\begin{abstract}
In this paper, an attempt to determine the effective thermal conductivity $\left(\mathrm{k}_{\mathrm{eff}}\right)$ of particulate filled polymer composites using finite element method (FEM) a powerful computational technique is made. A commercially available finite element package ANSYS is used for this numerical analysis. Three-dimensional spheres-in-cube lattice array models are constructed to simulate the microstructures of particulate filled polymer composites with filler content ranging from 2.35 to 26.8 vol $\%$. Composites with similar filler contents are then fabricated using compression molding technique by reinforcing micro-sized aluminium oxide $\left(\mathrm{Al}_{2} \mathrm{O}_{3}\right)$ in polypropylene (PP) resin. Thermal conductivities of these composite samples are measured according to the ASTM standard E-1530 by using the Unitherm ${ }^{\mathrm{TM}}$ Model 2022 tester. The experimentally measured conductivity values are compared with the numerical values and also with those obtained from existing empirical models. This comparison reveals that the FEM simulated values are found to be in reasonable good agreement with the experimental data. Values obtained from the theoretical model are also found to be in alignment with the measured values within percolation limit. Furthermore, this study shows that there is gradual enhancement in the conductivity of PP resin with increase in filler percentage. It is noticed that with addition of $26.8 \mathrm{vol} \%$ of filler, the $\mathrm{k}_{\text {eff }}$ of composite increases to around 6.3 times that of neat PP. This study validates the proposed model for $\mathrm{PP}-\mathrm{Al}_{2} \mathrm{O}_{3}$ composite system and proves that finite element analysis can be an excellent methodology for such investigations.
\end{abstract}

Keywords Polymer Matrix Composite, Polypropylene, Aluminium Oxide, Effective Thermal Conductivity, Finite Element Method

\section{Introduction}

Thermally conductive and electrically insulating polymer composites are largely used in electronic packaging. Recent requirement in electronic technologies of faster and denser circuits resulted in the miniaturization of transistors to obtain high performance, more transistors have to be integrated into a single device. Nevertheless, integration of such large number of transistors into a single device results in the escalation of power dissipation as well as an increase in heat flux in the devices. It is well known that the performance of such device is very much dependent upon its operating temperature. Hence, it is very important that the heat generated during the operation of such device is dissipated effectively and quickly so that the operating temperature remains within the desired level [1].

Either molecular orientation [2] or the addition of heat conductive fillers [3-5] can enhance thermal conductivity of polymers. In practice, however, manufacturing of polymers with specific orientation is not easy at all. Hence, addition of heat conductive fillers, such as particles or fibers, seems to be a more realistic solution. The thermal conductivity of polymer composites is improved by reducing its thermal barrier resistance in the direction of heat flow which results in the formation of thermal conductive network within the composite. As the conductive network forms, the composite shows percolation behavior. In addition to high thermal conductivity, low dielectric constant is also needed, as in application like printed circuit board; low dielectric constant helps to increase the velocity of signal propagation [6]. So the material used for these kinds of applications must have multi-functional properties. One approach of providing path for heat conduction through the composite and increasing mean thermal conductivity while maintaining low dielectric constant of the system involves addition of ceramic fillers with intrinsically high thermal conductivity and relatively low dielectric constant to polymers. In the literature, a lot of thermally conductive composite systems have been investigated by incorporating different type of ceramics filler such as $\mathrm{SiC}$ [7], $\mathrm{BN}$ [8], $\mathrm{AlN}$ [9], $\mathrm{Al}_{2} \mathrm{O}_{3}$ and $\mathrm{ZnO}$ [1] into various types of polymers. 
Apart from experimental investigations, to evaluate the $\mathrm{k}_{\mathrm{eff}}$ of composite materials analytically, several predictive models have been proposed in the past. For a two-component composite, the simplest alternatives would be the materials to be arranged in either series or parallel with respect to heat flow, which gives the upper or lower bounds of $\mathrm{k}_{\text {eff }}[10]$.

For parallel conduction model, there is

$$
k_{e f f}=\left(1-\phi_{f}\right) k_{p}+\phi_{f} k_{f}
$$

where, $k_{e f f}, k_{p}, k_{f}$ are the thermal conductivities of the composite, matrix and filler respectively and $\Phi_{f}$ is the volume fraction of filler.

For series conduction model, there is

$$
1 / k_{e f f}=\left(1-\phi_{f}\right) / k_{p}+\phi_{f} / k_{f}
$$

Maxwell-Euken model [11] assumes well dispersed small spherical filler within continues matrix to calculate the $\mathrm{k}_{\text {eff. }}$ The model is valid for low loading of filler. The expression is given by:

$$
\frac{k_{e f f}}{k_{p}}=\left(\frac{k_{f}+2 k_{p}+2 \phi_{f}\left(k_{f}-k_{p}\right)}{k_{f}+2 k_{p}-\phi\left(k_{f}-k_{p}\right)}\right)
$$

Bruggeman [12] derived an equation of effective thermal conductivity in terms of the solid loading for spherical fillers in a dilute suspension which is given by:

$$
1-\phi_{f}=\frac{k_{e f f}-k_{f}}{k_{p}-k_{f}}\left(\frac{k_{p}}{k_{e f f}}\right)^{\frac{1}{3}}
$$

All the models mentioned above are capable of estimating the $\mathrm{k}_{\mathrm{eff}}$ of particulate filled composites on the basis of volume fraction of the filler but none of the model has actually taken care of the arrangement of the filler particles within the matrix. However, this aspect has been considered in a recently proposed model [13]. This model assumed an arranged distribution of filler particles within the matrix body, and the expression for $\mathrm{k}_{\mathrm{eff}}$ as per this proposed model is given by:

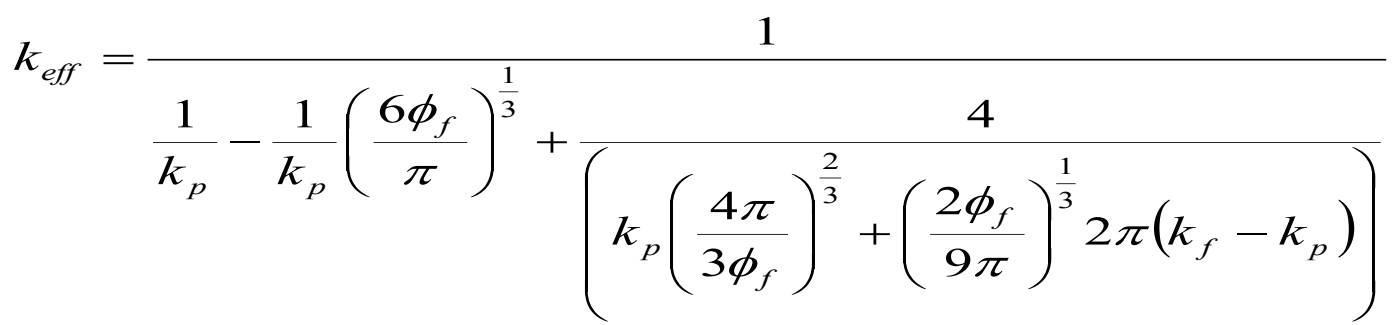

Most of the works reported are on experimental and analytical basis, though little work on the numerical study has also been done to predict the $\mathrm{k}_{\text {eff }}$ of such composite [10,14], which shows that FEM is an excellent tool to predict the effective thermal conductivity of the composite material.

In this context, the present research work is to study the effects of ceramic filler, $\mathrm{Al}_{2} \mathrm{O}_{3}$ in a thermoplastic polymer i.e., polypropylene on its heat conduction behavior. The $\mathrm{k}_{\text {eff }}$ of $\mathrm{PP}-\mathrm{Al}_{2} \mathrm{O}_{3}$ composites with different compositions are numerically evaluated and validated through measured values. Suitable theoretical and numerical model to predict $\mathrm{k}_{\text {eff }}$ of different matrix-filler combinations have been suggested in this study. It is expected that this study will be of importance for new packaging technologies of further increasing working domain and miniaturization of electronic devices. 


\section{Experimental Details}

\subsection{Materials}

Homopolymer polypropylene, most easily available resin belonging to the thermoplastic group of polymer, was used as a matrix material. PP is a thermoplastic which is also the most common commodity-plastic and has one of the highest consumptions because of its well-balanced physical and mechanical properties at a relatively low cost. It possesses very low density of $0.92 \mathrm{~g} / \mathrm{cm}^{3}$. In spite of its low thermal conductivity $(0.11 \mathrm{~W} / \mathrm{m}-\mathrm{K})$ and high coefficient of thermal expansion $\left(111.5 \times 10-6 /{ }^{\circ} \mathrm{C}\right)$, it possesses very low dielectric constant $(2.25$ at $1 \mathrm{MHz})$ which makes this polymer feasible for microelectronic applications. PP used in the present work is procured from Reliance Industries Limited located in Mumbai, India. $\mathrm{Al}_{2} \mathrm{O}_{3}$ is purchased from M/s Alfa Aesar Limited-Beijing, China. $\mathrm{Al}_{2} \mathrm{O}_{3}$ powder has a density of 3.89 $\mathrm{gm} / \mathrm{cm}^{3} . \mathrm{Al}_{2} \mathrm{O}_{3}$ is chosen because of its moderate heat conducting nature $(35 \mathrm{~W} / \mathrm{m}-\mathrm{K})$, dielectric constant $(9.8$ at 1 $\mathrm{MHz})$ and coefficient of thermal expansion $\left(8.1 \times 10^{-6} /{ }^{\circ} \mathrm{C}\right)$.

\subsection{Composite Fabrication}

Compression molding technique is used to fabricate the composites. Rheomix 600 batch mixer with chamber volume $90 \mathrm{~cm}^{3}$ is used to melt and mix PP and $\mathrm{Al}_{2} \mathrm{O}_{3}$ particles $(90-100 \mu \mathrm{m})$. In present case the mixing temperature is set to $190^{\circ} \mathrm{C}$ whereas mixing time is of $12 \mathrm{~min}$, the temperature and time may differ for different sets of materials. The mixing is done as per ASTM standard D-2538. As the mixing is over, the material is taken out from the chamber and is cut into small pieces which are then taken for compression molding. Materials are kept in die which is used to make a composite sheet of thickness $3 \mathrm{~mm}$ and area $60 \times 60 \mathrm{~mm}^{2}$. With the help of hydraulic press, the material is pressed with a pressure of $150 \mathrm{~kg} / \mathrm{cm}^{2}$ while maintaining a temperature of $190^{\circ} \mathrm{C}$ for around three minutes. After that it is allowed to get water cooled. Compression moulding is done as per ASTM D-256 standard. Later the disc type specimens (diameter $50 \mathrm{~mm}$, thickness $3 \mathrm{~mm}$ ) are cut from the sheet. Composites of 10 different compositions with different volume fraction are prepared.

\subsection{Experimental Determination of Thermal Conductivity}

Unitherm $^{\mathrm{TM}}$ Model 2022 is used to measure thermal conductivity of a variety of materials. These include polymers, ceramics, composites, glasses, rubbers, some metals, and other materials of low to medium thermal conductivity. The tests are in accordance with ASTM E-1530 Standard. A sample is held under a uniform compressive load between two polished surfaces, each controlled at a different temperature. The lower surface is part of a calibrated heat flow transducer. The heat flows from the upper surface, through the sample, to the lower surface, establishing an axial temperature gradient. After reaching thermal equilibrium, the temperature difference across the sample is measured along with the output from the heat flow transducer. These values and the sample thickness are then used to calculate the thermal conductivity. The temperature drop through the sample is measured with temperature sensors in the highly conductive metal surface layers on either side of the sample. For one-dimensional heat conduction the formula can be given by;

$$
Q=k S \frac{d T}{L}
$$

The thermal resistance of a sample can be given by;

$$
R=\frac{L}{k S}
$$

where $\mathrm{R}$ is the thermal resistance of the sample along its thickness. From Eq (7), effective thermal conductivity can be evaluated as:

$$
k=\frac{L}{R S}
$$

In Unitherm ${ }^{\mathrm{TM}} 2022$ the heat flux transducer measures the $\mathrm{Q}$ value and the temperature difference can be obtained between the upper plate and lower plate. Thus the thermal resistance can be calculated between the upper and lower surfaces. Giving the input value of thickness and taking the known cross-sectional area, the thermal conductivity of the samples can be calculated using Eq. (8).

\section{Results and Discussion}

\subsection{Numerical Analysis and Concept of Finite Element Method ANSYS}

The finite element method (FEM) is a powerful tool used in numerical methods to calculate approximate solutions to mathematical problems so that it can simulate the responses of physical systems to various forms of excitation. In order to make a thermal analysis, three-dimensional physical models with spheres-in-cube in a lattice array have been used to simulate the microstructure of composite materials for different filler concentrations. Furthermore, the $\mathrm{k}_{\text {eff }}$ of the polypropylene composites filled with micro sized $\mathrm{Al}_{2} \mathrm{O}_{3}$ particle up to 26.8 vol $\%$ are numerically determined by using ANSYS.

\subsection{Description of the Problem}

Fig.1 illustrates the heat flow direction and the boundary conditions for the particulate-polymer composite body considered for the analysis of this conduction problem. The temperature at the nodes along the surface $\mathrm{ABCD}$ is prescribed as $100^{\circ} \mathrm{C}$ and the ambient convective heat transfer coefficient is assumed to be $2.5 \mathrm{~W} / \mathrm{m}^{2}-\mathrm{K}$ at a room 
temperature of $27^{\circ} \mathrm{C}$. The other surfaces parallel to the heat flow direction are all assumed adiabatic. The unknown temperatures at the interior nodes and on the other boundaries are obtained with the help of ANSYS.

In this analysis, it is assumed that the composites are macroscopically homogeneous, the thermal contact resistance between the filler and the matrix is negligible and the composite lamina is free from voids. The temperature profiles are obtained for the composites with different particulate concentrations ranging from $2.356 \%$ to $26.8 \%$. Fig 2 presents typical temperature profile diagram for one such composition with filler loading of 26.8 vol \%. Similar temperature profiles are obtained for other compositions as well. The $\mathrm{k}_{\mathrm{eff}}$ of composites are numerically estimated from the corresponding temperature profiles. A comparison of $\mathrm{k}_{\mathrm{eff}}$ of the composites obtained by FEM, Rule of mixture, Maxwell model, Bruggeman's model, proposed mathematical model and the measured values are graphically represented in Fig 3. It is evident that there is appreciable increase in $\mathrm{k}_{\text {eff }}$ as the concentration of $\mathrm{Al}_{2} \mathrm{O}_{3}$ particle is increasing. With addition of 26.8 vol $\%$ of $\mathrm{Al}_{2} \mathrm{O}_{3}$ particle, thermal conductivity of polypropylene increased from 0.11 $\mathrm{W} / \mathrm{m}-\mathrm{K}$ to $0.693 \mathrm{~W} / \mathrm{m}-\mathrm{K}$ which is an enhancement of about 6.3 times with respect to that of neat PP.

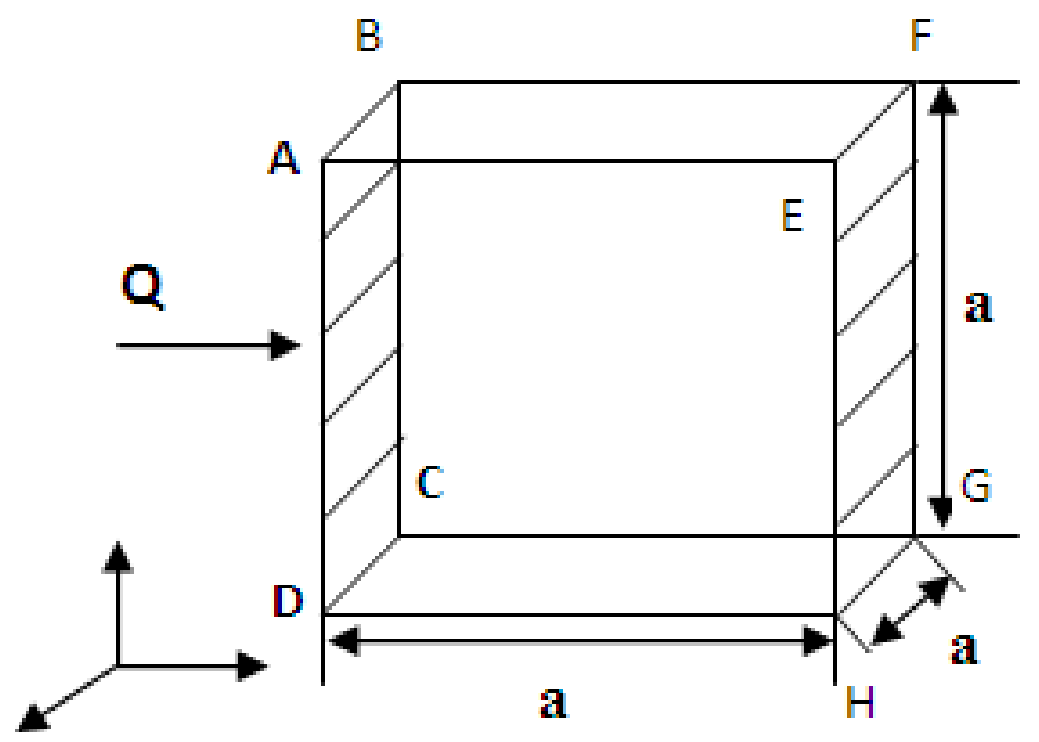

Figure 1. Boundary condition

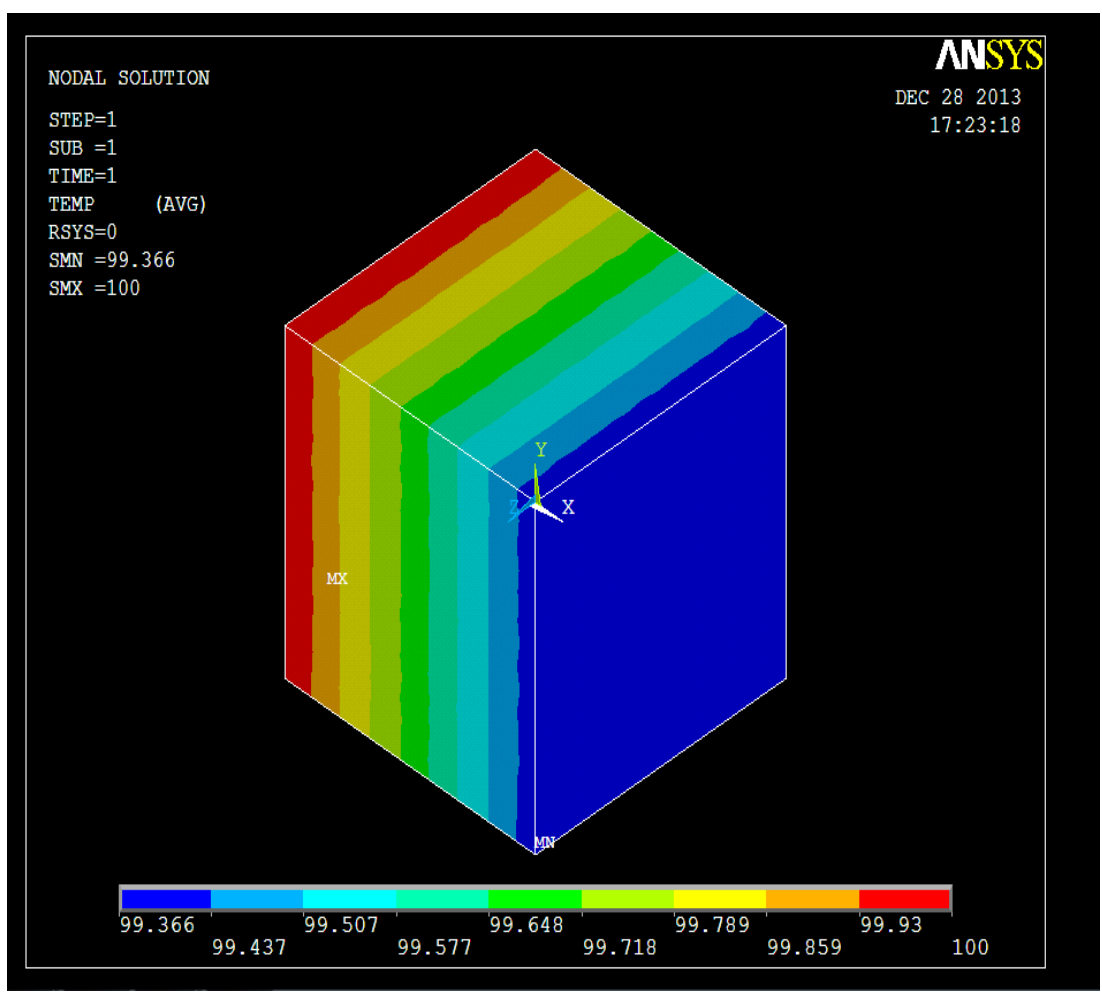

Figure 2. Typical temperature profile diagram for $26.8 \mathrm{vol} \%$ of filler 


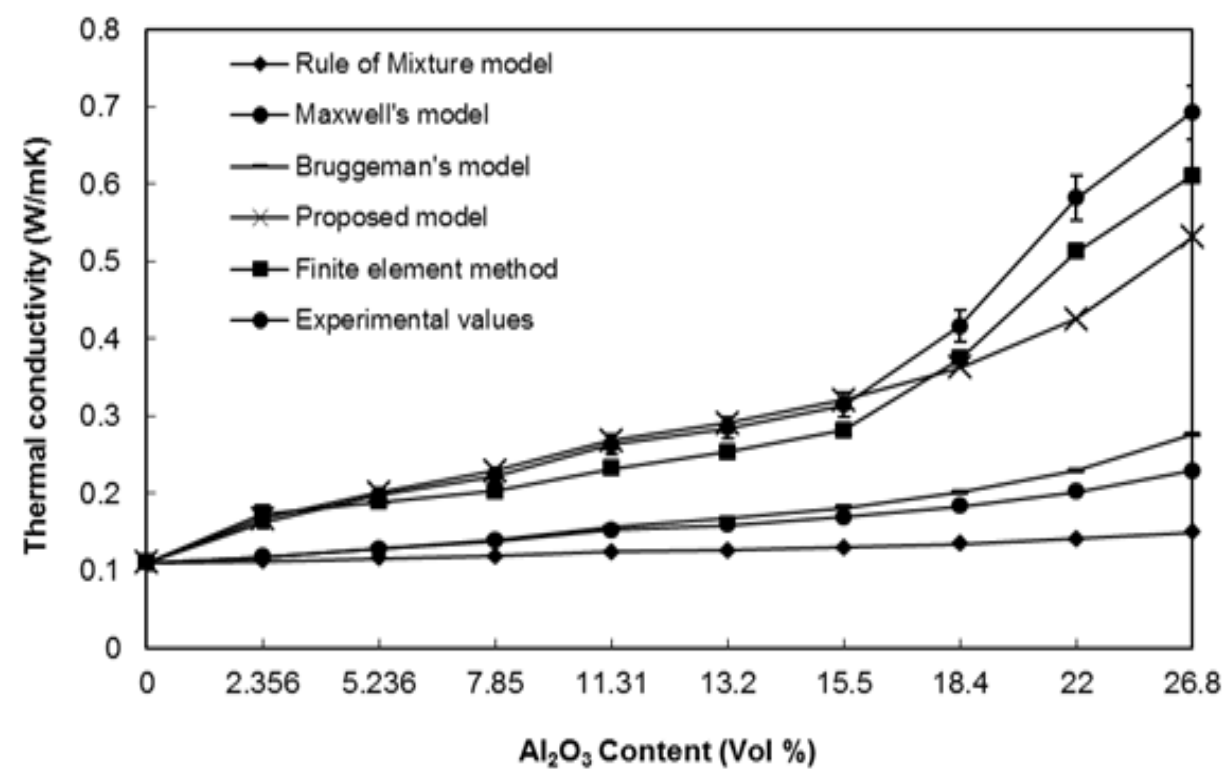

Figure 3. Comparison of effective thermal conductivity of $\mathrm{PP} / \mathrm{Al}_{2} \mathrm{O}_{3}$ composite obtained from analytical, numerical and experimental methods.

Table 1. Associated error of different analytical model and numerical model

\begin{tabular}{|c|c|c|c|c|c|c|}
\hline \multirow[b]{2}{*}{$\begin{array}{l}\text { Sample } \\
\text { No. }\end{array}$} & \multirow{2}{*}{$\begin{array}{c}\mathrm{Al}_{2} \mathrm{O}_{3} \\
\text { Content } \\
(\mathrm{Vol} \%)\end{array}$} & \multicolumn{5}{|c|}{ Absolute error (\%) } \\
\hline & & Rule of mixture & $\begin{array}{l}\text { Maxwell's } \\
\text { model }\end{array}$ & Brugmann's model & $\begin{array}{l}\text { Proposed mathematical } \\
\text { model }\end{array}$ & Numerical model \\
\hline 1 & 2.356 & 30.9 & 27.7 & 27.6 & 2.45 & 6.74 \\
\hline 2 & 5.236 & 41.1 & 35 & 34.5 & 2.03 & 4.06 \\
\hline 3 & 7.85 & 46.6 & 38.1 & 37.2 & 2.69 & 8.96 \\
\hline 4 & 11.31 & 52.8 & 42.2 & 40.7 & 1.90 & 11.38 \\
\hline 5 & 13.2 & 55.6 & 44 & 41.2 & 2.46 & 10.92 \\
\hline 6 & 15.5 & 58.6 & 46.2 & 42.3 & 2.22 & 10.51 \\
\hline 7 & 18.4 & 67.5 & 56 & 51.7 & 12.7 & 10.09 \\
\hline 8 & 22 & 86.1 & 65.3 & 60.6 & 26.9 & 12.02 \\
\hline 9 & 26.8 & 78.3 & 66.9 & 60.2 & 23.37 & 11.83 \\
\hline
\end{tabular}

It is also clear that the value obtained from FEM are in better agreement with the measured value in comparison to those obtained from other theoretical models. The percentage error for the analytical models and numerical model with respect to measured values are shown in table 1.

It is clear from the table that the maximum absolute error registered in the simulated value is about $12 \%$, whereas none of the other models predicted the values as precisely for the entire range of filler content. Though the model developed by the authors in their earlier investigation are in closest approximation with measured values, this approximation is only up to percolation threshold and when the filler loading increases further, proposed model starts under-estimating the measured values significantly. It is because while developing the correlation, the authors had not taken care of the inter-connectivity between the particles, which built up in real composite at higher filler loading, but in case of numerical model as the filler content is increasing, inter particle space between the filler decreases, resulting in reduction of less conductive matrix material between them which is same is the case in actual composite.

Also, the difference between the simulated/calculated values and the values obtained by Rule of mixture, Maxwell's model and Bruggeman's model may be attributed to the fact that these models do not consider the distribution pattern of the filler particles within the matrix body, while the FEM analysis and proposed model do. Those are the two reasons why numerical model is predicting the $\mathrm{k}_{\mathrm{eff}}$ value so precisely for the entire range of filler loading. Thus, it proves that finite element analysis can be an excellent methodology for such investigations.

\section{Conclusions}

This numerical investigation on thermal conductivity of 
polypropylene composites filled with micro-sized aluminium oxide particles has led to the following conclusions:

1) Finite element method can be gainfully employed to determine $k_{\text {eff }}$ of these composite with different amount of filler content. A good agreement of FEM results with those obtained from experimental efforts validates the usefulness of this numerical method.

2) Successful fabrication of polypropylene composites filled with $\mathrm{Al}_{2} \mathrm{O}_{3}$ particles by compression molding technique is possible.

3) The model proposed by the authors is proved to be successful for different matrix filler combinations.

4) Incorporation of $\mathrm{Al}_{2} \mathrm{O}_{3}$ particles results in increase of thermal conductivity of polypropylene and thereby improves its conduction capability. With addition of 26.8 vol $\%$ of $\mathrm{Al}_{2} \mathrm{O}_{3}$ particle, the thermal conductivity increases as high as by about $530 \%$ as compared to virgin $\mathrm{PP}$.

5) This class of $\mathrm{Al}_{2} \mathrm{O}_{3}$ particle filled PP composites can find potential applications in microelectronics, printed circuit boards, encapsulations etc.

\section{REFERENCES}

[1] Sim L C, Ramanan S R, Ismail H, Seetharamu K N, Goh T J. Thermal characterization of $\mathrm{Al}_{2} \mathrm{O}_{3}$ and $\mathrm{ZnO}$ reinforced silicone rubber as thermal pads for heat dissipation purposes. Thermochimica Acta, 430(1-2), 155-165, 2005.

[2] Peng S, Landel R. Induced Anisotropy of Thermal Conductivity of Polymer Solids under Large Strains. Journal of Applied Polymer Science, 19(1), 49-68, 1975.

[3] Weindenfeller B, Hofer M, Schilling F R. Thermally conductivity, thermal diffusivity and specific heat capacity of particle filled polypropylene. Composite: Part A: Applied science and manufacturing, 35(4), 423-429, 2004.
[4] Tavman I H. Thermal and Mechanical Properties of Copper Powder Filled Poly (ethylene) Composites. Journal of Powder Technology, 91(1), 63-67, 1997.

[5] Boudenne A, Ibos L, Fois M, Gehin E, Majeste J C. Thermophysical properties of polypropylene/Aluminium Composites. Journal of Polymer Composite: Part B: Polymer Physics, 42(4), 722-732, 2004.

[6] Yung K C, Zhu B L, Yue T M, Xie C S. Development of epoxy-matrix composite with both high-thermal conductivity and low-dilectric constant via hybrid filler systems. Journal of Applied Polymer Science, 116(1), 518-527, 2010.

[7] Zhou W, Yu D, Min C, Fu Y, Guo X. Thermal, dielectric, and mechanical properties of $\mathrm{SiC}$ particles filled linear low-density polyethylene composites. Journal of Applied Polymer Science, 112(3), 1695-1703, 2009.

[8] Zhou W, Qi S, An Q, Zhao H, Liu N. Thermal conductivity of boron nitride reinforced polyethylene composites. Material Research Bulletin, 42(10) 1863-1873, 2007.

[9] Ohashi M, Kawakami S, Yokogawa Y, Lai G C. Spherical aluminum nitride fillers for heat-conducting plastic packages. Journal of the American Ceramic Society, 88(9), 2615-2618, 2005.

[10] Kumlutas D, Tavman I H. A numerical and experimental study on thermal conductivity of particle filled polymer composites. Journal of Thermoplastic Composite Material, 19(4), 441-454, 2006.

[11] Maxwell J C. A Treatise on Electricity and Magnetism. $3^{\text {rd }}$ Edition, Dover, New York, 1954.

[12] Bruggeman G. Calculation of various physics constants in heterogeneous substance I dielectricity constants and conductivity of mixed bodies from isotropic substance. Annalen der physic, 416(7), 636-664, 1935.

[13] Agrawal A, Satapathy A. Development of a heat conduction model and investigation on thermal conductivity enhancement of AlN/Epoxy composites. Procedia Engineering, 51, 573-578, 2013.

[14] Veyret D, Cioulachtjian S, Tadrist L, Pantoloni J. Effective thermal conductivity of a composite material: A numerical approach. Journal of Heat Transfer, 115(4), 866-871, 1993. 